\title{
Design and Analysis of Steel Reel Shaft by Using FEA
}

\author{
Nebojša RAŠOVIĆ, Adisa VUČINA, Remzo DEDIĆ
}

\begin{abstract}
This paper describes the analysis of steel reel shaft as drive shaft in a process of umbilical spooling of wire rope. There is a need to investigate shaft behaviour in the conditions of increasing workload. The aim is to investigate avoiding possible redesign or enabling redesign with minimal costs. Stress analysis has been carried out by using finite element analysis (FEA) and results are compared with the analytically calculated values. Finite element analysis has been carried out using maximum stress criteria and the area of potential failure is found. The main objective of this paper is to find balance in results between "design by rule" and "design by analysis". Design by rule provides rules on how to design a steel reel shaft using analytical equations and other strict rules from design elements. Design by analysis provides rules on using numerical analysis, typically finite element analysis to design a steel reel shaft. The steel reel shaft has been geometrically modelled using SolidWorks. To check all stresses, linear static analysis is done using DSS Simulation and Ansys.
\end{abstract}

Keywords: drive shaft; failure analysis; finite element analysis; stress state analysis

\section{INTRODUCTION}

Structural steel can be defined as linear elastic isotropic material. This material is suitable for shaft design in order to transmit power and torque. In this work, focus is on the reel drive shaft, which is made by this structural steel. The main role of the shaft is running reel in order to twist special wire ropes to umbilical spooling (Fig. 1).

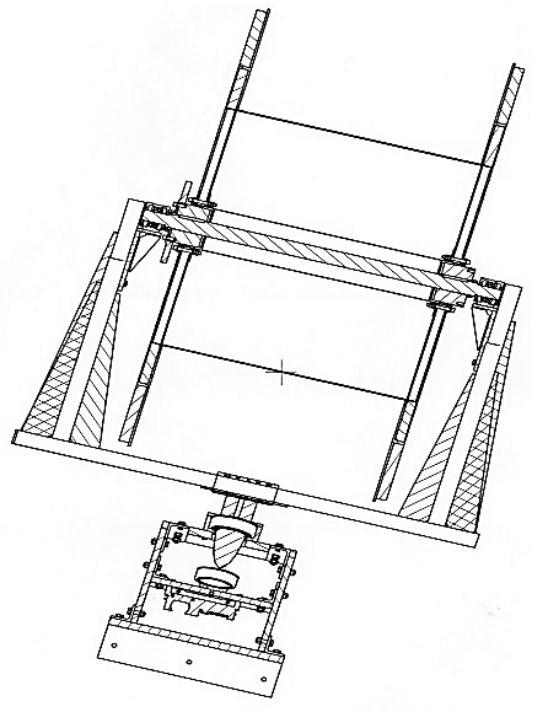

Figure 1 Drive shaft with steel reel

The steel reels for umbilical spooling of special wire ropes have large diameters and this entire structure works under great loads. Because of that, entire structure is very large and heavy presenting a great challenge to the normal function performance. The EDC company d.o.o. Mostar (Engineering, Design and Construction) asked to investigate behaviour of the drive shaft and bearings in the case of increasing weight of the wire ropes. Total weight of the current structure is $50 \mathrm{kN}$ and it is planned to increase weight by $50 \mathrm{kN}$ and total weight would be around $100 \mathrm{kN}$. The main task of this paper is to check whether the current design can withstand a new workload without changing the construction or with minimal changes and costs. Specifically, the question is whether the drive shaft with bearings withstands new maximum stress in case of weight increase.
Therefore, the goal is to keep current bearings, shaft and all connectors. Stress analysis relies on the ability to make accurate predictions of the material strength under loading conditions [1]. The basic data used in the calculation were: power on the drive shaft $P=1,5 \mathrm{~kW}$ and shaft rate $n=2 \mathrm{~min}^{-1}$. The entire assembly of drive shaft with bearings used to calculate the stress state is shown in Fig. 2.

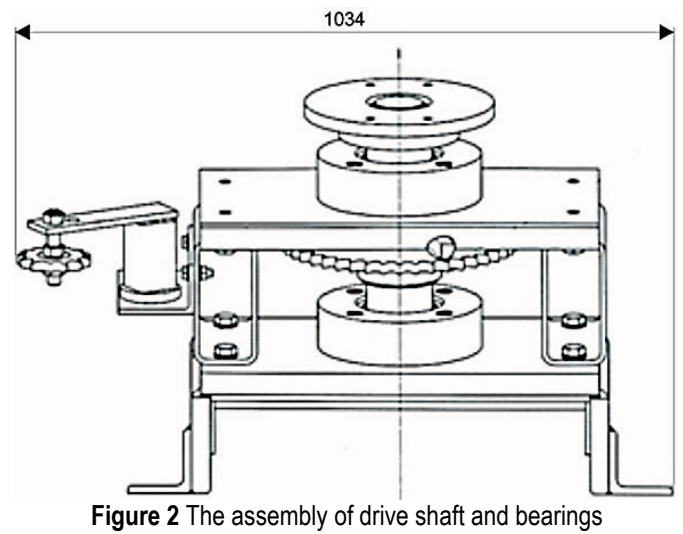

\section{OBJECTIVE AND SCOPE}

For calculating stress state, total load is decomposed into components: axial, normal and circular. These loads lead to generation of compression, flexion and torsion stresses in the shaft cross section. For calculation purpose, it is necessary to select the type of support, apply loads, to generate diagrams of flexion, compression and torsion and evaluate the safety factors for critical section [2, 3]. In order to know new conditions, the investigation includes the following objectives: analytical stress calculation, FEA stress calculation and comparing both results [4-6].

\subsection{Dimensions and Mechanical Properties of the Shaft}

Drive shaft has $400 \mathrm{~mm}$ of length and $80 \mathrm{~mm}$ of diameter as the main model dimensions. The shaft also has two lateral wedge slots at the right side and one slot at the upper and the same one at the bottom side (Fig. 3). Mechanical properties of the structural steel St52-3 are given in Tab. 1. 
The drive shaft has been modelled by SolidWorks 2017 using multiple main parameters such as radius of the shaft and the length of the shaft. They create revolve feature as the main feature of the model besides various smaller features like chamfers and sockets.

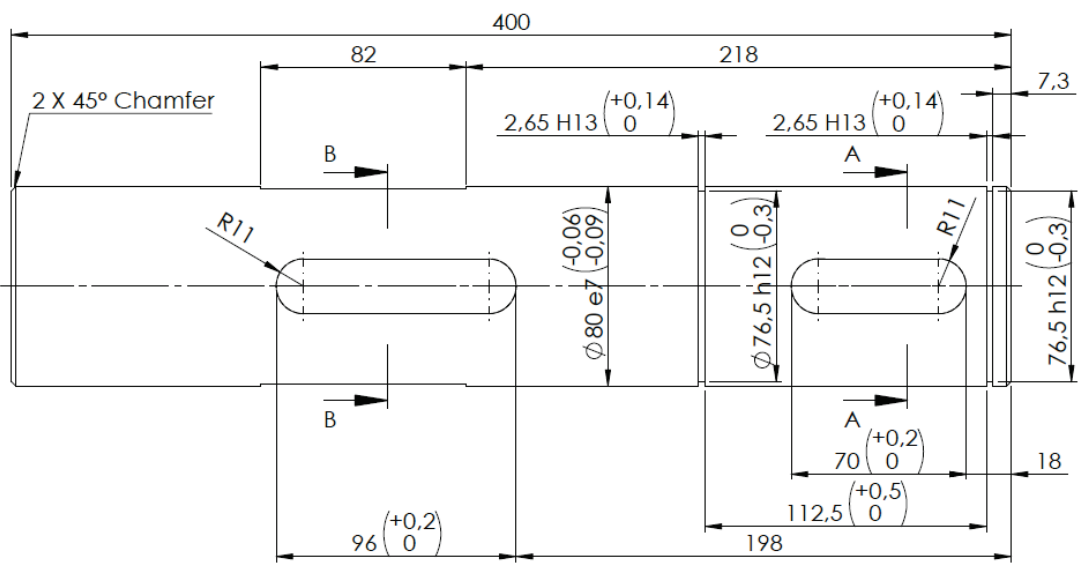

Figure 3 Detail drawing of the drive shaft

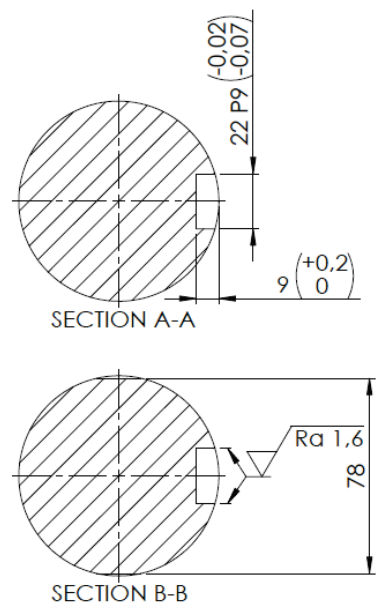

SECTION B-B
Table 1 Mechanical properties of the shaft material

\begin{tabular}{|c|c|c|c|c|}
\hline \multicolumn{3}{|c|}{$\begin{array}{l}\text { Total length of the shaft } \\
\mathrm{Ls}_{\mathrm{s}} / \mathrm{mm}\end{array}$} & \multicolumn{2}{|l|}{400} \\
\hline \multicolumn{3}{|c|}{$\begin{array}{l}\text { Main radius of the shaft } \\
\qquad \mathrm{r} / \mathrm{mm}\end{array}$} & \multicolumn{2}{|l|}{40} \\
\hline \multicolumn{3}{|c|}{ Material of the shaft } & \multicolumn{2}{|c|}{$\begin{array}{l}\text { St52-3 } \\
\text { (DIN StructuralSteel) }\end{array}$} \\
\hline Elastic & Poisson's & Mass & Shear & Yield \\
\hline $\begin{array}{l}\text { Modulus } \\
\mathrm{MPa}\end{array}$ & $\begin{array}{c}\text { Ratio } \\
/\end{array}$ & $\begin{array}{l}\text { Density } \\
\mathrm{kg} / \mathrm{m}^{3}\end{array}$ & $\begin{array}{l}\text { Modulus } \\
\mathrm{MPa}\end{array}$ & $\begin{array}{l}\text { Strength } \\
\mathrm{MPa}\end{array}$ \\
\hline 210000 & 0,28 & 7800 & 79000 & 315 \\
\hline
\end{tabular}

\subsection{Boundary Conditions}

The drive shaft is supported by two spherical roller bearings 22216 E SKF Explorer. This type of bearing has great axial load carrying capacity. SKF spherical roller bearings are able to accommodate heavy axial loads and even accommodate purely axial loads. According to that, the basic static load rating of this bearing is $270 \mathrm{kN}$ and bearing mass is $2,1 \mathrm{~kg}$. Material of the shaft is structural steel St52-3 with yield strength of $315 \mathrm{MPa}$. As the drive shaft is subjected to the torsion moment, a moment is applied about z-axis (Fig. 4).
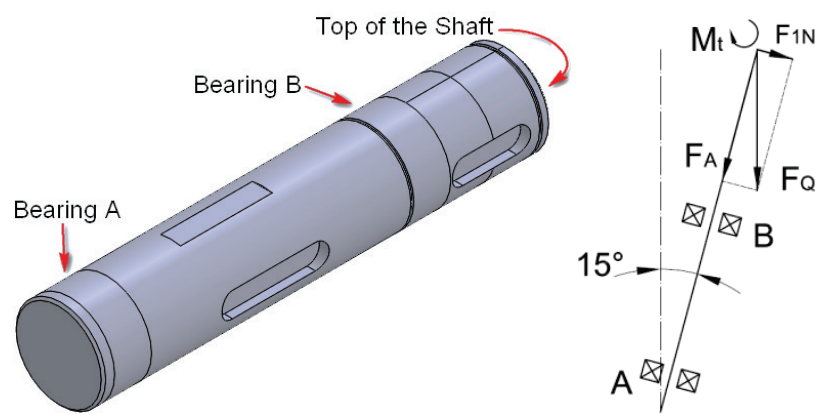

Figure 4 Schematic view of the loads

Likewise, the drive shaft is subjected to the total input load of $F_{\mathrm{Q}}=100 \mathrm{kN}$. This load has been divided into two components, axial applied along z-axis and normal applied along $y$-axis. The angle between shaft axis and ordinate is
15 degrees (Fig. 4). Jacobian element with sixteen points and global element size of $8 \mathrm{~mm}$ are creating mesh.

\subsection{Analytical Calculation of the Load on Shaft}

The power on the drive shaft is a known value as well as shaft rate. Maximum torsion moment is got from the expression:

$M_{\mathrm{t}}=\frac{P}{\omega}=\frac{1500 \mathrm{~W}}{0,2 \mathrm{~s}^{-1}}=7500 \mathrm{Nm}$

$\omega=\frac{\pi \cdot n}{30}=\frac{\pi \cdot 2}{30}=0,2 \mathrm{~s}^{-1}$

If it is looked closer from Fig. 4, axial and normal components of the input load could be expressed as:

$F_{\mathrm{A}}=F_{\mathrm{Q}} \cdot \cos 15^{\circ}=100000 \mathrm{~N} \cdot \cos 15^{\circ}=96592 \mathrm{~N}$

$F_{\mathrm{N}}=F_{\mathrm{Q}} \cdot \sin 15^{\circ}=100000 \mathrm{~N} \cdot \cos 15^{\circ}=25881 \mathrm{~N}$

Total moment of flexion that occurs at the bearing point B within assembly of drive shaft and additional lever that is linking the reel is:

$M_{\mathrm{fB}}=F_{\mathrm{N}} \cdot L=25881 \mathrm{~N} \cdot 1500 \mathrm{~mm}=38821500 \mathrm{Nmm}(5)$

The force that is induced in the shaft only causes flexion:

$F_{1 \mathrm{~N}}=\frac{M_{\mathrm{fB}}}{L_{1}}=\frac{38821500 \mathrm{Nm}}{90 \mathrm{~mm}}=431350 \mathrm{~N}$

Flexion stress caused by normal component:

$\sigma_{\mathrm{f}}=\frac{M_{\mathrm{fB}}}{W}=\frac{38821500 \mathrm{Nm}}{35137 \mathrm{~mm}^{3}}=1104,86 \mathrm{MPa}$ 
Axial moment of resistance:

$W=\frac{\pi \cdot\left(d-t_{1}\right)^{3}}{32}=\frac{\pi \cdot(80-9)^{3}}{32}=35137 \mathrm{~mm}^{3}$

Compression stress caused by axial component, where the section area has approximate value:

$\sigma_{\mathrm{p}}=\frac{F_{\mathrm{A}}}{A}=\frac{96592 \mathrm{~N}}{4828 \mathrm{~mm}^{2}}=20 \mathrm{MPa}$

$A=\frac{d^{2} \cdot \pi}{4}-b \cdot t_{1}=\frac{80^{2} \cdot \pi}{4}-9 \cdot 22=4828 \mathrm{~mm}^{2}$

Torsion stress caused by moment of torsion:

$\tau_{\mathrm{t}}=\frac{M_{\mathrm{t}}}{W_{\mathrm{t}}}=\frac{7500000 \mathrm{Nm}}{70275 \mathrm{~mm}^{3}}=106,72 \mathrm{MPa}$

Torsion moment of resistance:

$W_{\mathrm{t}}=\frac{\pi \cdot\left(d-t_{1}\right)^{3}}{16}=\frac{\pi \cdot(80-9)^{3}}{16}=70275 \mathrm{~mm}^{3}$

\section{NUMERICAL CALCULATION}

The linear finite elements analysis is used for determining the stress state, displacement and strain of the shaft for the given linear elastic material [7]. The aim of stress analysis using FEA was to verify stress calculations done before [8]. The criterion for decision whether the construction is in failure condition was: if the Von-Mises stress is greater than the yield strength of the material, then the construction is in failure condition.

\subsection{Finite Element Analysis}

Static structural analysis as a part of FEA was conducted (Fig. 5) in DSS Simulation 2017 and Ansys 16.0 $[9,10]$. The loads applied to the shaft during the finite element analysis were: axial component of $96592 \mathrm{~N}$, normal component of $431350 \mathrm{~N}$ and torsion moment of $7500 \mathrm{Nm}$. The shaft mass was $15,41 \mathrm{~kg}$.

Fig. 6 shows the finite element model of the analysed shaft. The model represents a continuum discretized by the three-dimensional 16-node finite elements, with three degrees of freedom in each node. Discretization may be described as a process by which the given body is subdivided into equivalent system of finite elements [11].

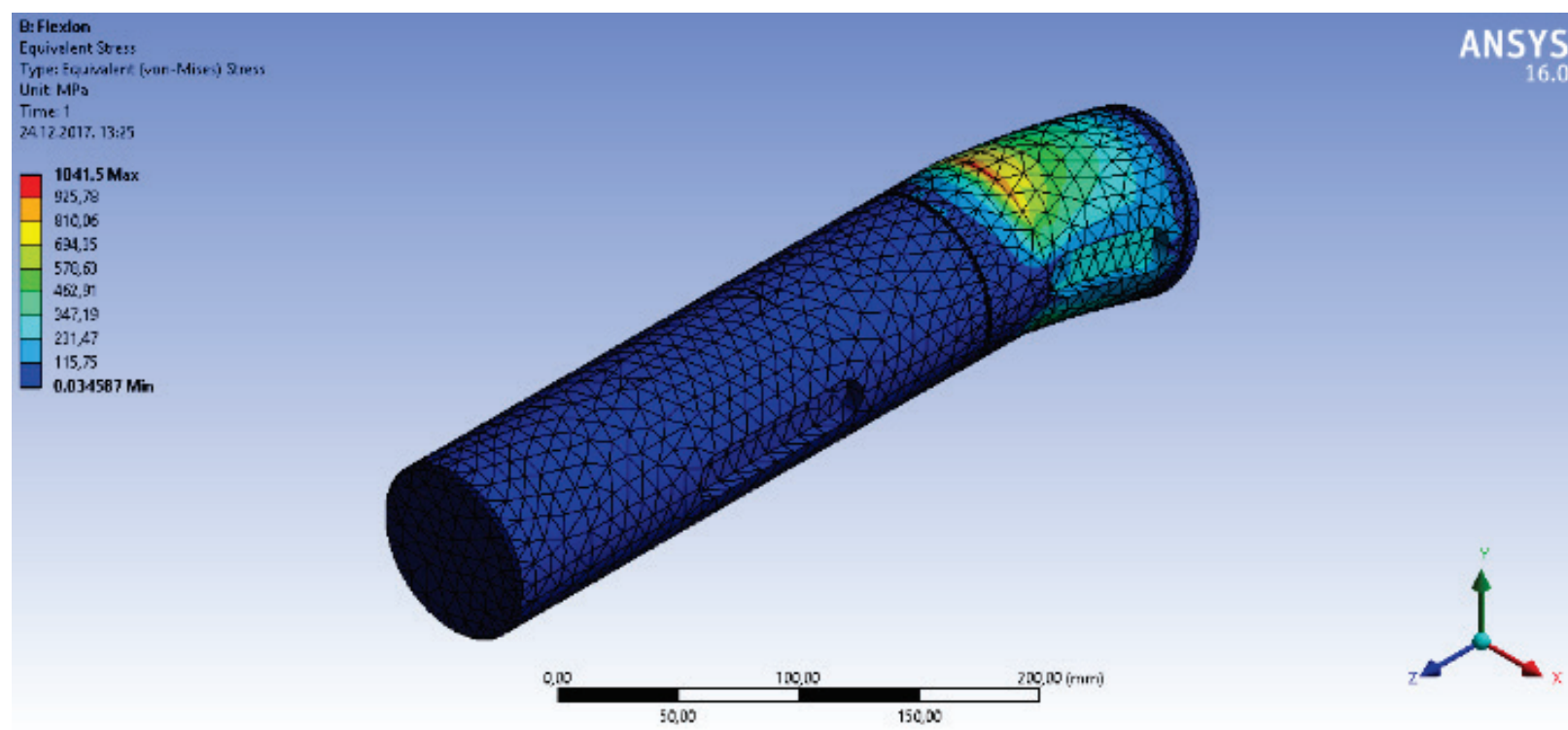

Figure 5 Finite element analysis results for the applied load

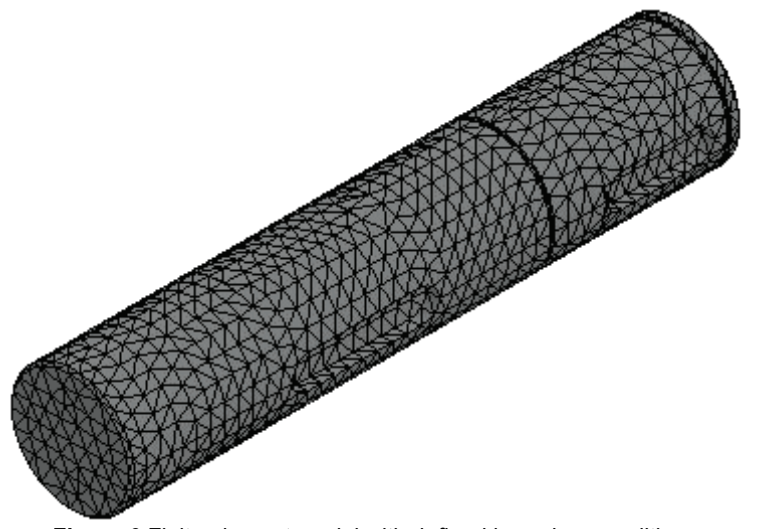

Figure 6 Finite element model with defined boundary conditions

\subsection{Results and Discussion}

According to the applied load and material properties, stress results are expressed in Tab. 2.

As the numerical results show, it can be seen that stress values were close to the analytical calculated ones. By finite element analysis, maximum stress values are occurring at the cross section near bearing support B (Fig. 4 ), so it is called critical cross section. This area need to be further investigated in order to get precise information about material behavior under known load case.

The maximum numerical normal stress caused by normal component in the critical point of the shaft is 1193 $\mathrm{MPa}$, which gives low safety factor comparing with the yield strength of $315 \mathrm{MPa}$. Thus, it is obvious that flexion stress causes excessive strain in the material of the shaft. 
From the results in the case of flexion stress, the structure has been deeply exposed to the possible failure. Both analyses, analytical and numerical, are similarly showing very high flexion stress values.

Table 2 FEA stress state results

\begin{tabular}{|c|c|c|c|c|}
\hline & \multicolumn{2}{|c|}{ DSS Simulation2017 } & \multicolumn{2}{|c|}{ Ansys 16.0} \\
\hline \multirow{3}{*}{$\frac{\Xi}{\stackrel{0}{x}}$} & $\begin{array}{c}\text { von Mises } \\
\sigma / \mathrm{MPa}\end{array}$ & 1193 & $\begin{array}{c}\text { von Mises } \\
\sigma / \mathrm{MPa}\end{array}$ & 1041,5 \\
\hline & $\begin{array}{l}\text { URES } \\
v / \mathrm{mm}\end{array}$ & 0,4426 & $\begin{array}{l}\text { URES } \\
v / \mathrm{mm}\end{array}$ & 0,46483 \\
\hline & $\begin{array}{c}\text { ESTRN } \\
\varepsilon / \%\end{array}$ & 0,004437 & $\begin{array}{c}\text { ESTRN } \\
\varepsilon / \%\end{array}$ & 0,0059115 \\
\hline \multirow{3}{*}{ 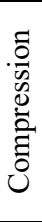 } & $\begin{array}{c}\text { von Mises } \\
\sigma / \mathrm{MPa}\end{array}$ & 48,06 & $\begin{array}{c}\text { von Mises } \\
\sigma / \mathrm{MPa}\end{array}$ & 44,734 \\
\hline & $\begin{array}{l}\text { URES } \\
v / \mathrm{mm}\end{array}$ & 0,01127 & $\begin{array}{l}\text { URES } \\
v / \mathrm{mm}\end{array}$ & 0,012094 \\
\hline & $\begin{array}{c}\text { ESTRN } \\
\varepsilon / \%\end{array}$ & 0,0001786 & $\begin{array}{c}\text { ESTRN } \\
\varepsilon / \%\end{array}$ & 0,00024291 \\
\hline \multirow{3}{*}{ 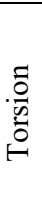 } & $\begin{array}{c}\text { von Mises } \\
\sigma / \mathrm{MPa}\end{array}$ & 246,4 & $\begin{array}{c}\text { von Mises } \\
\sigma / \mathrm{MPa}\end{array}$ & 252,82 \\
\hline & $\begin{array}{l}\text { URES } \\
\mathrm{v} / \mathrm{mm}\end{array}$ & 0,0923 & $\begin{array}{l}\text { URES } \\
v / \mathrm{mm}\end{array}$ & 0,10204 \\
\hline & $\begin{array}{c}\text { ESTRN } \\
\varepsilon / \%\end{array}$ & 0,0008086 & $\begin{array}{c}\text { ESTRN } \\
\varepsilon / \%\end{array}$ & 0,001282 \\
\hline
\end{tabular}

The rest of stresses, compression and torsion are within allowed limits. The maximum numerical compression stress caused by axial component in the critical point of the shaft is $48,06 \mathrm{MPa}$, which gives high safety factor comparing with the yield strength of $315 \mathrm{MPa}$. The same is true for stress caused by torsion moment, where the maximum numerical torsion stress is 252,82 $\mathrm{MPa}$, which results with safety factor greater than 1,2 comparing with the yield strength of $315 \mathrm{MPa}$. The factor of safety under the combined action of flexion and torsional stress as the highest calculated numerical values is defined by the following equation:

$S=\frac{S_{\sigma} \cdot S_{\tau}}{\sqrt{S_{\sigma}^{2}+S_{\tau}^{2}}}=0,25<S_{\min }=1,2$

Based on calculated safety factor, potential failure of structure is confirmed. Since safety factor is too low, it has been considered to add material in the load path. As the following part of the results, Fig. 7 shows regions that carry the most of the load. In that term, stress distribution has been located near bearing $B$, which unambiguously indicates on area of critical section.

However, there is a possibility for further investigation in the form of longitudinal and lateral directions of stress measuring in correlation with chamfer length at the top. The goal is to define whether some regions that carry most of the load have tendency for their changing in terms of reducing or transforming themselves.

For a closer look, depending on stress distribution over the longitudinal surface line, it is interesting to investigate how chamfer length and stress concentration [12] impact on shaft, especially on critical cross section at point of bearing B. Adopted measurement region is area from the top of the shaft to the cross line of critical section (Fig. 8). To determine the effect of chamfer length and stress concentration on stress distribution, finite element analysis is carried out.
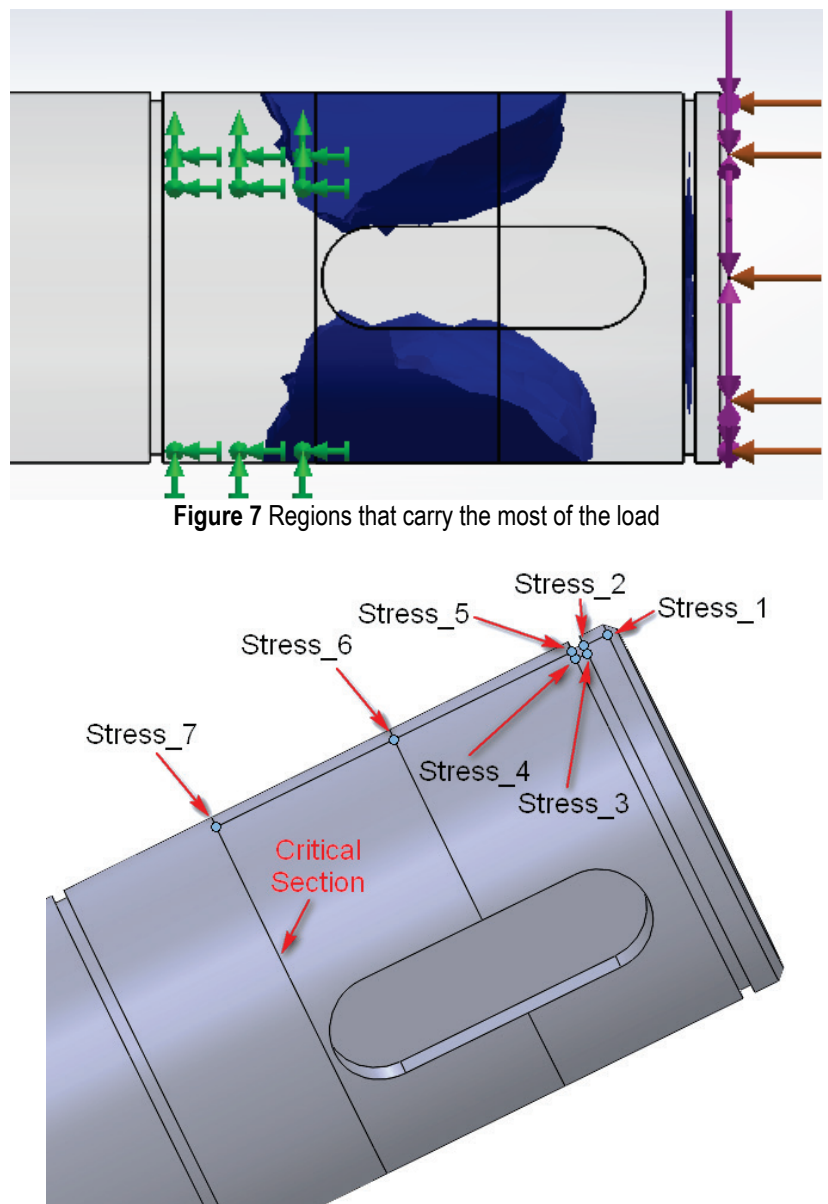

Figure 8 Measuring process of the stress distribution over longitudinal line

It had been set seven measuring locations for tracking stress distribution depending on various values of chamfer length at the top of the shaft. The assumption was that the stress distribution depends of the chamfer length. There is some possibility to decrease stress at the bearing B, as in radius corner case $[13,14]$.

It is desirable to set the sensor gauges in order to obtain measured values of stress in interesting points. It is decided to set seven measuring points based on the shaft configuration. The goal is to obtain as little stress value as possible in the point stress_7 (Fig. 8). The starting point for this measuring is also the influence of stress concentration at various configuration places. The smallest chamfer length is $0,5 \mathrm{~mm}$ and the largest is $4 \mathrm{~mm}$. The results of measuring are as the following five scenarios shown in Fig. 9, Fig. 10 and Fig. 11 respectively.

Fig. 9 shows impact of the chamfer length on flexion stress. It is recognized that stress values are similar and almost uniform at the first five points (stress_1, stress_2, stress_3, stress_4 and stress_5) and after that there is big stress jump at point six (stress_6), especially at point seven (stress_7). It is concluded that changes in chamfer length do not imply flexion stress.

Impact of the chamfer length on compression stress is presented in Fig. 10. In this case, by increasing the chamfer length, compression stress is decreased in points three (stress_3) and four (stress_4) especially. However, there is no effect on stress value at the end (stress_6 and stress_7). 
Therefore, it can be concluded that changes in chamfer length do not implicate compression stress decreasing.

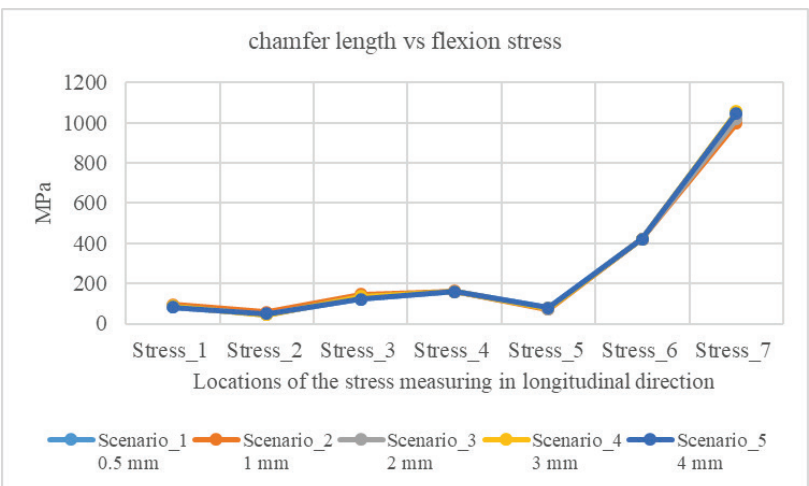

Figure 9 Impact of the chamfer length on flexion stress

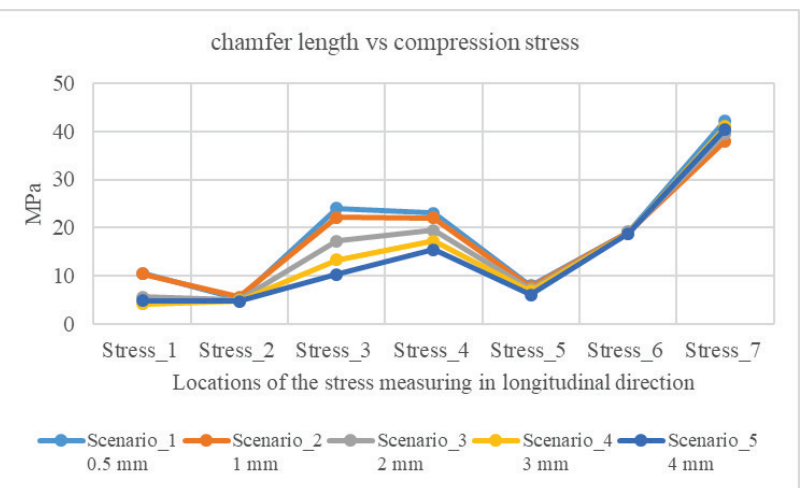

Figure 10 Impact of the chamfer length on compression stress

Fig. 11 shows impact of the chamfer length on twisting stress. In this case, there is a little turnaround in stress values, but without significant changes. It means that changes in chamfer length do not imply torsion stress decreasing.

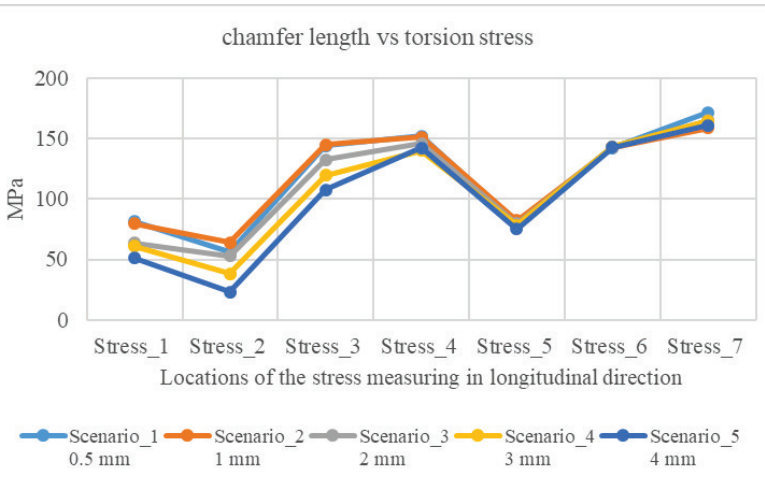

Figure 11 Impact of the chamfer length on torsion stress

From the general overview, the previous three figures confirmed that the stress distribution is almost uniform over longitudinal line. If it is looked closer, flexion stress at the first five stress points is approximately uniform regardless of the small gap along diameter. In this gap, there is increased stress concentration, but there are no significant changes of the stress values. The last two stress points measure the greatest stress values and they exceed the allowed limit. This fact precisely describes that input load is too high for the current structure configuration and its components. Compression and torsion stresses have similar growth trend for the first five stress points, but the main difference is that the maximum stress is no greater than the allowed at any point of measuring including the last point.

Besides longitudinal stress distribution there was a need for stress measuring in the lateral line of critical cross section. For this measuring type, it was set five measuring locations in critical cross section (Fig. 12).

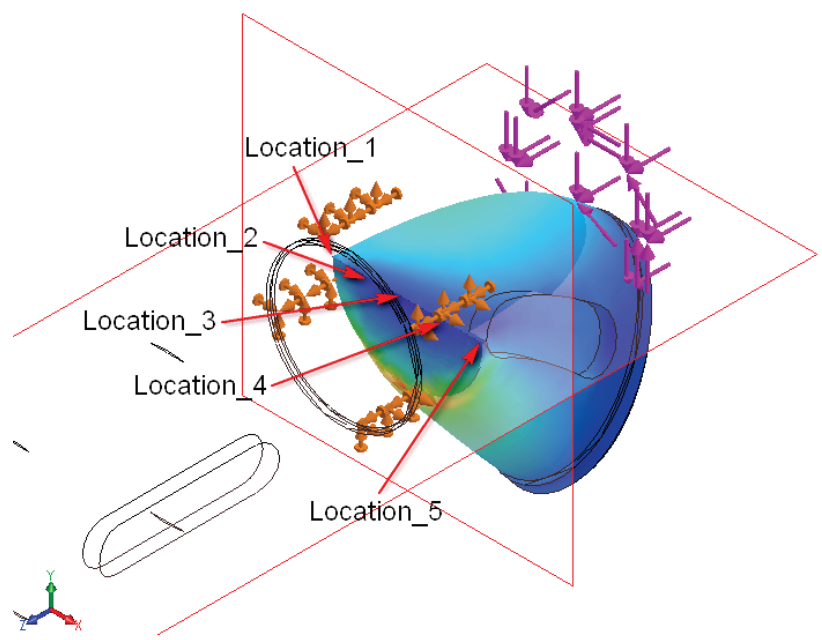

Figure 12 Layout of the measuring locations

From Fig. 13, it is obvious that there are no significant changes in the stress values along lateral line in critical cross section. It can be concluded that section core is not under failure load. Note that location 1 and location 5 are the most loaded points caused by torsion moment.

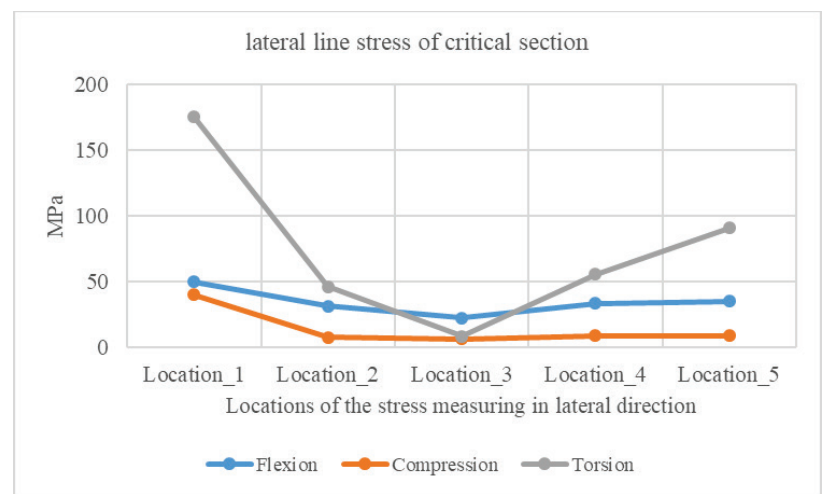

Figure 13 Three stress types in the lateral line of critical section

As the final criterion of this analysis was the overview of reaction forces in the bearing B support. Similar to previous results, it was possible to get reaction forces from the finite element analysis. Values from both FEA packages are shown in Tab. 3 and it is obvious that results are similar. Resultant force is $445000 \mathrm{~N}$ by DSS Simulation or $445510 \mathrm{~N}$ by Ansys.

Table 3 Force reaction in the support bearing $B$

\begin{tabular}{|r|c|c|c|c|}
\hline & $\begin{array}{c}X \text { Axis } \\
F_{X} / \mathrm{N}\end{array}$ & $\begin{array}{c}Y \text { Axis } \\
F_{Y} / \mathrm{N}\end{array}$ & $\begin{array}{c}Z \text { Axis } \\
F_{Z} / \mathrm{N}\end{array}$ & $\begin{array}{c}\text { SUM } \\
F_{\text {RES }} / \mathrm{N}\end{array}$ \\
\hline $\begin{array}{r}\text { Simulation } \\
\text { Total: }\end{array}$ & $-85,5$ & 435000 & -94200 & 445000 \\
\hline Ansys 16.0 & & & & \\
Total: & $-40,573$ & 435480 & -94037 & 445510 \\
\hline
\end{tabular}

However, both resultant forces overcome basic static load $C_{0}=270 \mathrm{kN}$ for the spherical roller bearing. This is 
the final result which confirms that the current structure is not capable to carry new load of $100 \mathrm{kN}$.

\section{CONCLUSION}

This paper analysed the drive shaft under the increased input load defined from the company of EDC. The current shaft design did not satisfy input load and it is not adequate for planned application because it has insufficient mechanical properties and large amount of defects near critical cross section. Specifically, the investigation found the high value of flexion stress, which produced a drastic deformation. In addition, it is concluded that there is no impact of chamfer length change on decreasing of stress values in critical section.

As previously mentioned, the following guidelines are strongly recommended:

- change shaft geometry in terms of increasing its main revolution radius,

- use adequate materials (with higher yield strength),

- change bearings in accordance with shaft (with higher basic static load $C_{0}$ ).

\section{Acknowledgements}

The results presented in this paper were conducted in cooperation with EDC company (Engineering, Design and Construction) d.o.o. Mostar.

\section{REFERENCES}

[1] Dalvi, S. D., Hariom, Chandrababu, D., Satav, S., \& Vijoykumar (2017). Failure analysis of a carbon steel roller shaft of continuous pad steam machine. Case Studies in Engineering Failure Analysis, 9 118-128. https://doi.org/10.1016/J.CSEFA.2017.11.001

[2] Barsoum, I., Khan, F., \& Barsoum, Z. (2014). Analysis of the torsional strength of hardened splined shafts. Materials \& Design, (1980-2015), 54, 130-136. https://doi.org/10.1016/J.MATDES.2013.08.020

[3] Timerbaev, N. F., Sadrtdinov, A. R., \& Safin, R. G. (2017). Software Systems Application for Shafts Strength Analysis in Mechanical Engineering. Procedia Engineering, 206 1376-1381. https://doi.org/10.1016/J.PROENG.2017.10.648

[4] Urquiza, G., García, J. C. C., González, J. G. G., Castro, L., Rodríguez, J. A. A., Basurto-Pensado, M. A. A., \& Mendoza, O. F. F. (2014). Failure analysis of a hydraulic Kaplan turbine shaft. Engineering Failure Analysis, 41 108-117. https://doi.org/10.1016/j.engfailanal.2014.02.009

[5] Zambrano, O. A., Coronado, J. J., \& Rodríguez, S. A. (2014). Failure analysis of a bridge crane shaft. Case Studies in Engineering Failure Analysis, 2(1), 25-32. https://doi.org/10.1016/J.CSEFA.2013.12.002

[6] Zangeneh, S., Ketabchi, M., \& Kalaki, A. (2014). Fracture failure analysis of AISI 304L stainless steel shaft. Engineering Failure Analysis, 36 155-165. https://doi.org/10.1016/J.ENGFAILANAL.2013.09.013

[7] Momčilović, D., Odanović, Z., Mitrović, R., Atanasovska, I., \& Vuherer, T. (2012). Failure analysis of hydraulic turbine shaft. Engineering Failure Analysis, 20 54-66. https://doi.org/10.1016/j.engfailanal.2011.10.006

[8] Beňo, P., Kozak, D., \& Konjatić, P. (2014). Optimization of thin-walled constructions in CAE system ANSYS. Technical Gazette, 21(5), 1051-1055.

[9] James Prasad Rao, B., Srikanth, D. V., Suresh Kumar, T., \& Sreenivasa Rao, L. (2016). Design and analysis of automotive composite propeller shaft using FEA. Materials Today: Proceedings, 3(10), 3673-3679. https://doi.org/10.1016/J.MATPR.2016.11.012

[10] Mohan, S. \& Vinoth, M. (2016). Design and Analysis of Composite Drive Shaft for Automotive Application. MiddleEast Journal of Scientific Research Recent Innovations in Engineering Technology, Management \& Applications. https://doi.org/10.5829/idosi.mejsr.2016.24.RIETMA118

[11] Kaviprakash, G., Lawrence, I. D., Kannan, C. R., \& Regan, A. P. (2014). Design and analysis of composite Drive shaft for automotive application. International Journal of Engineering Research \& Technology, 3(11), 429-436.

[12] Bajic, D., Momčilović, N., Maneski, T., Balac, M., Kozak, D., \& Ćulafić, S. (2017). Numerical and experimental determination of stress concentration factor for a pipe branch model. Technical Gazette, 24(3), 687-692. https://doi.org/10.17559/TV-20151126222916

[13] van Zyl, G. \& Al-Sahli, A. (2013). Failure analysis of conveyor pulley shaft. Case Studies in Engineering Failure Analysis, 1(2), 144-155. https://doi.org/10.1016/J.CSEFA.2013.04.011

[14] Göksenli, A. \& Eryürek, I. B. (2009). Failure analysis of an elevator drive shaft. Engineering Failure Analysis, 16(4), 1011-1019. https://doi.org/10.1016/j.engfailanal.2008.05.014

\section{Contact information:}

Nebojša RAŠović, PhD, Assistant Professor

(Corresponding author)

Faculty of Mechanical Engineering, Computing and Electrical Engineering University of Mostar,

Matice hrvatske b.b., 88000 Mostar, Bosnia and Herzegovina nebojsa.rasovic@sve-mo.ba

\section{Adisa VuČINA, PhD, Full Professor}

Faculty of Mechanical Engineering, Computing and Electrical Engineering University of Mostar,

Matice hrvatske b.b., 88000 Mostar, Bosnia and Herzegovina

adisa@sve-mo.ba

\section{Remzo DEDIĆ, PhD, Full Professor}

Faculty of Mechanical Engineering, Computing and Electrical Engineering University of Mostar

Matice hrvatske b.b., 88000 Mostar, Bosnia and Herzegovina

remzo.dedic@sve-mo.ba 